Paideusis

\title{
Authentic Autonomy: A Practical Reasoning Critique of Directive Moral Education
}

\section{Scott Priestman}

Volume 14, Number 2, 2001

URI: https://id.erudit.org/iderudit/1072795ar

DOI: https://doi.org/10.7202/1072795ar

See table of contents

Publisher(s)

Canadian Philosophy of Education Society

ISSN

0838-4517 (print)

1916-0348 (digital)

Explore this journal

Cite this article

Priestman, S. (2001). Authentic Autonomy: A Practical Reasoning Critique of Directive Moral Education. Paideusis, 14(2), 5-19.

https://doi.org/10.7202/1072795ar viewed online.

https://apropos.erudit.org/en/users/policy-on-use/ 


\section{Authentic Autonomy: \\ A Practical Reasoning Critique of Directive Moral Education ${ }^{1}$}

\section{Scott Priestman, University of British Columbia}

\section{Abstract}

Programs of directive moral education (DME) that attempt to pre-rationally condition particular values are often criticized as violating autonomy. A common defense of DME is that if individuals, later in life, can respond to reasons, then autonomy has not been violated. In this paper I argue that this defense is a weak one because it does not pay sufficient attention to what is involved in responding to reasons. By adopting a theory of practical reasoning, I show that the reasons we can respond to are determined by the values that we hold. As such, the source of those values is crucial. If we are responding to reasons based merely upon values we have been conditioned to hold, then autonomy is compromised. We must, rather, hold values that we have chosen for our own. In this way I argue that authenticity is a necessary component of autonomy.

\section{Introduction}

With a perceived increase in violence, crime and moral decay in our society, there is a call, from many fronts, to increase and strengthen the moral teachings we offer our young. Though agreement is wide-spread that schools can have an important role to play in these teachings, there is little agreement as to what exactly schools should be doing in moral education. Some argue that we should be teaching kids certain core values (Carr 1991, Metcalf 1971). Others claim that we should be developing in children a respect for other people (and sometimes, other creatures as well) and an understanding of what obligations and responsibilities come with this respect (Boyd 1992, Wilson 1990). There are some who think that what is really needed is a curriculum that will enhance the care we feel for one another (Ayim 1991, Noddings 1984). Part of the disagreement around what should be done is a disagreement regarding what exactly a morally mature person is. Depending upon what we are hoping to achieve, our ways of doing moral education will be significantly different.

My goal in this paper is not to settle the question about what moral education should be. Rather, it is to explore one aspect of the morally mature person: autonomy. The hope is that with a better understanding of the morally mature person, we will be closer to a reasonable and agreed-upon conception of 
moral education. I am going to argue that within a context of moral maturity, a crucial component of autonomy is authenticity. ${ }^{2}$ As such, any teaching that strives to develop moral capacities and dispositions must be one that, at the very least, does not hinder authenticity (and one which, preferably, develops it).

To get at these issues of autonomy and authenticity, I will explore questions surrounding programs of directive moral education (hereafter DME). I begin the paper by exploring a defense of DME as found in a work by George Sher and William J. Bennett. These authors argue that DME is not necessarily indoctrinative. I will argue that their position is a weak one because it rests on an impoverished notion of autonomy. To counter their position, I explore a theory of practical reasoning that explains what is involved in our responding to reasons. I conclude by looking at Stanley Benn's theory of autonomy that successfully incorporates a component of authenticity.

\section{Sher and Bennett}

In their 1982 article Moral Education and Indoctrination, George Sher and William J. Bennett argue against the position that all directive moral education must be indoctrinative. The authors cite, then argue against, two common arguments used to support this position. One is that such directive moral education violates students' autonomy. The second is that directive moral education involves sectarian teaching inappropriate to a pluralistic society. They begin their exploration by clarifying what they mean by directive moral education. They illustrate their meaning by providing a list of virtues that "the schools should help students realize the importance of' (p. 666). Amongst these principles and traits we find such concepts as self-discipline, trustworthiness, truth-telling, courage, honour, etc. The list they provide is taken from an Ohio school-board document and is meant only as an example of the type of thing they are talking about; it is not meant to be an exhaustive list.

For the moment we will not concern ourselves with the content of the list, but look instead to the justification for why such a list is acceptable and necessary. In teaching such virtues, educators are encouraged not only to model the specific behaviour, but to demand it from each of their students (and to punish its absence). While Sher and Bennett accept it might be useful to explain why such virtues are important, efforts to habituate these virtues can and must extend beyond rational persuasion (p. 667). It is at this point that we first encounter the possibility that students' autonomy is being violated. Sher and Bennett begin to address this question by asking whose autonomy is being violated, the child's or the future 
adult's? They explore each in turn. For the purpose of this paper, I will pick up their discussion of how the future adult's autonomy might be violated.

The charge of indoctrination levelled at DME, in this context, can be seen as follows: by conditioning children to behave in a certain way, it restricts the possibility for the future adult to act autonomously. Because we pre-rationally condition children to favour certain beliefs and values, the range of choices open to the future adult is diminished and so their autonomy has been violated. Sher and Bennett reject this initial formulation by claiming that just because we are habituated to perform a certain action, it does not necessarily prevent us from later exploring the reasons why we do the action, and to critique the adequacy of these reasons. Thus, we are still potentially autonomous simply because we retain the capacity to assess the reasons and act in accordance with these reasons.

They then turn to a more complex formulation of the charge of indoctrination and explore the claim that autonomy demands not only acting in accordance with reasons, but also being motivated by an awareness of these reasons. In other words, if the agent would not have performed the action without the previous directive moral education, then the action is not autonomously done. Against this type of claim, it is not sufficient that one is merely responding to reasons. This position demands, further, that one is motivated by the perception of these reasons.

It is not entirely clear to me what the authors are arguing here. I take their point to be something like the discussion in Kantian ethics of overdetermined actions. For Kant, there can be a number of factors motivating one towards action. The act is moral, however, only if the motivation provided by one's sense of duty is (or would be) strong enough, on its own, to move the agent to so act (for more on this discussion, see Herman 1993, p. 23-44). I think Sher and Bennett are trying to get at something like this with this hypothetical objection. The objection states that all sorts of different factors can be involved in moving one towards some action. However, that action is autonomous only if the perception of the reasons justifying this action are (or would be), on their own, strong enough to move the agent.

Sher and Bennett attack this objection on three levels. First, they claim that the 'motivational energy' deemed as a necessary component of autonomy is an obscure concept. This motivational energy is that force that moves an agent to act (this could include, for example, some response to reasons, some desire that the agent has or some conditioning that the agent has been subjected to). Though not explicitly stated, I think this charge of obscurity is meant to cast doubt on the actual existence of any such motivational energy. Secondly, they do not accept that even 
if such a thing exists, it is a necessary component of autonomy. Thirdly, even if we overlook the first two problems, they claim directive moral education still does not violate autonomy. Rather it simply does not contribute to autonomy: "[f]ar from establishing that directive techniques are pernicious, it at best establishes that they are morally neutral" (p. 670).

Having, they believe, overcome this argument, the authors take a step further and claim that their scheme of DME will in fact promote autonomy. In essence, they anticipate a situation in which the appreciation of reasons will compete against other desires in determining how to act. If DME can supplement the desire or motive to follow the course dictated by the appreciation of reasons, then one is more likely to be acting autonomously: "It may neutralize or eliminate what would otherwise be a competing motive, and so may enable one's appreciation of reasons to affect one more strongly" (p. 670).

It is unclear to me how the authors think this will enhance autonomy. What they are proposing is to habituate certain 'virtues' so strongly that one will not succumb to the temptations of other competing desires or motives. But if one is unable to respond to other desires or motives, how is one going to respond to reasons? Here we get a sense that the authors' conception of 'reasons' is an incomplete one. They fail to explain what is involved in responding to reasons. Are we affected by reasons in the same way that we are affected by a desire? Do we simply observe some feature of the world and automatically respond to it? What is it about the perception of a reason that motivates us to act or judge in a certain way? The authors do not address these questions and so do not appreciate the role that values play in our response to reasons [a fuller exploration of this point will follow in section 3 below].

While this extra step (of claiming that DME has the potential to promote autonomy) is not crucial in their argument, it is very instructive in how it points to what is missing from their conception of autonomy. What they have in mind is a situation of competing motives. Motive $x$, supplied by DME, may be met by motive $y$ which is some desire, which in turn is met by motive $z$, something induced by fear or jealously say (both of which have not been produced by DME). What Sher and Bennett believe is that conditioning students to act according to $\mathrm{x}$ will "clear away obstacles so that the energy supplied by reasons can suffice" (p. 671). In other words, having been habituated to do $x$, we will be less likely seduced by the desires of $y$ or the fear of $z$. But what of the case where there are good grounds to choose some competing motive? What if the act the student has been trained to choose, $x$, is only one of a number of permissible actions? By their very own 
arguments, Sher and Bennett claim the student will be pre-rationally conditioned to favour $\mathrm{x}$. Solely in relation to $\mathrm{x}$, we still retain the capacity to assess reasons. But by having $\mathrm{x}$ inculcated, there will be cases where we are less able to recognize and respond to good reasons for doing other things.

To illustrate this point more clearly, let us consider an example. Imagine a society that wants each of its citizens to become a part of a particular religion, Anglican say. To this end, they pre-rationally condition each and every one of their youth to choose this path: all the youth are forced to attend Anglican services, to study in Anglican schools and to act in accordance with Anglican values. However, once the youth reach a certain age, they are given the freedom to decide for themselves whether they wish to continue as part of the particular faith community they were conditioned to accept. If they continue as Anglicans, are they doing so autonomously? There can be good reasons to so continue; one's faith community might do excellent work in certain segments of society, one's friends are members of this Church, one's self-identity is wrapped up with the religion.

According to Sher and Bennett's definition, such reasons provide the grounds for seeing this choice as autonomous. But simply to admit that there are good reasons for a choice is not to say that an agent, acting freely, would have made that choice. It is true that the agent retains his capacity to respond to reason. However, the comfort and inertia brought on by being in this position (that was reached through conditioning) provides a reason, perhaps the dominant reason, to continue in that position. If, without the initial conditioning, this person would never have made this choice, it is questionable whether the choice is autonomously made. Further, imagine that with similar experiences of a number of other faith communities, the individual would have overwhelmingly chosen another. Imagine too that there are strong reasons why the individual might otherwise be critical of this group (he is a strong advocate for social justice issues, for example, and finds his particular community lacking tolerance towards certain marginalized groups). Here we have even more grounds to doubt the autonomy of the choice to remain Anglican, even though the individual is responding to reasons that support the choice.

The point of the previous example is to show that Sher and Bennett's defense of DME runs the danger of being circular. Advocates of the position claim there is no violation of autonomy because, later in life, individuals will be able to respond to reasons. But if a response to reasons is going to be at all meaningful, then the values that lie behind this responding must be open to critical evaluation. If such values are conditioned in a way that makes it unlikely that they can or will be 
questioned, then we have cause to be concerned about the violation of autonomy.

My contention is not that DME should never be used. I agree with Sher and Bennett (and most other moral educators dating back to Aristotle) that sometimes $\mathrm{DME}$ is necessary (and so justified). My disagreement with the authors arises out of what is going on when we do use DME. Sher and Bennett argue that there is no violation of autonomy in a DME project. I am claiming there can be depending on how open to critical evaluation the conditioned values are. Because my position is more attuned to the potential dangers of DME, I am more concerned with establishing limits about when DME is justifiably used.

There is not adequate space in this paper to delve into the question of what this limit should be. I agree with R.M. Hare (1964) that DME is necessary in introducing young children to the language of morality. I also agree with Harvey Siegel (1991) that DME is necessary to get students to appreciate the force of reasons. I agree with Sher and Bennett that DME should never involve "immoderate humiliation or pain" (p. 676). But what of their condition that DME should not "impair a child's later ability to respond to moral reasons" (p. 676)? My claim is that this is always a danger. Conditioned values always run the risk of limiting the types of reasons that one can respond to. That Sher and Bennett think there can be DME that totally avoids this possibility is an indication that they do not adequately understand what is involved in responding to reasons. Further, it is evidence that they do not fully appreciate the potential dangers of conditioning values.

\section{The Nature of A Good Reason}

For me, the most serious problem with Sher and Bennett's account is their lack of understanding regarding how one responds to reasons. In fleshing-out what this involves, I will show that the authors do not take adequate account of the role values play in our response to reasons. As such, they do not adequately see the dangers involved in conditioning certain values. By being alerted to these dangers, we will more adequately see the importance of the source of our values and the important role that authenticity plays in autonomy.

In his 1997 book Beyond Neutrality, Sher builds upon the responsivenessto-reasons conception of autonomy that he and Bennett presented in their 1982 article. In Beyond Neutrality, Sher argues that autonomy involves responding to good (enough) reasons. He takes the common conception of an autonomous agent being one who is self-directing and builds upon this: "autonomous agents are selfdirecting in the more stringent sense of exercising their will on the basis of good 
reasons" (Sher 1997, p. 48). He builds in the good enough criterion because he wants to avoid any theory that demands an agent act from the best possible reasons.

To demonstrate his conception of autonomy, Sher offers two examples to show what he means by good (enough) reasons. In one, he offers a situation in which a young man must choose between getting married or dedicating himself to a career (1997, p. 54). Either option, he claims, can be chosen autonomously. This is so because the value that we normatively attribute to both pursuits (marriage and career) is sufficient to provide good enough grounds to follow either path.

The second example is that of a man who must choose between having lifesaving surgery or avoiding it because of the post-operative pain that he would have to endure $(1997$, p. 53$)$. In this scenario, Sher claims that there can only be one autonomous choice, accepting to undergo the surgery. He claims that there cannot be good enough reasons to avoid the surgery and thus it cannot be chosen autonomously. Though it is reasonable to want to avoid pain, when contrasted with the value of saving one's own life, the avoidance of pain cannot be the decisive motivating factor.

To be charitable to Sher, we can read this second example as typifying a situation in which the post-operative pain will not be too severe. Many of us, I think, can imagine situations in which excessive pain and limited quality of life would be sufficient to reasonably lead us not to choose the surgery. Though Sher does not make this explicit, we can read his example as ruling out these extreme cases. However, his failure to acknowledge that there could be such extreme cases is indicative of a weakness in his position. Sher seems not to notice that good reasons do not exist in some objective, metaphysical realm. Rather, reasons are good ones for particular people in specific situations.

Notice how similar his second example is to a standard example in many bio-medical ethics classes; the Jehovah's Witness who refuses life-saving surgery because she does not want a blood-transfusion. If this were set in the context of someone not liking needles, or being squeamish of blood-transfusions, then Sher (I suspect) would claim that the choice was not autonomously made. However, when set in the context of saving one's immortal soul, there certainly is strong enough reason to want to avoid the surgery. Many of us may not agree that a bloodtransfusion harms our immortal souls. However, we can appreciate that for someone who does hold such a belief/value, this will provide more than strong enough reason to avoid the surgery. The point of this example is to show that given the same facts about the world, people can reasonably respond differently depending upon the values that they hold. ${ }^{3}$ 
The question I am trying to answer here is what makes a reason a good one? For Sher, reasons appear to be some fact(s) about the world to which we respond and are thus motivated to act in one way or another. What he fails to account for is what provides this motivating force. How do facts about the world move us to act in one way or another? A fuller conception of reasons can be found in Jerrold Coombs' 1986 Presidential Address to the Philosophy of Education Society (Coombs 1987). Coombs questions (among other things) what sort of thing is to count as a reason for acting.

In answering this question, he borrows Stephen Darwall's explication of reason in its normative sense (because he is concerned with what constitutes a good reason). Darwall claims that reasons have two components. The first is a normative aspect, which grounds judgements about what an agent ought to do, all things considered. The second is a motivational aspect, the awareness of which can lead an agent to favour a given action (Darwall 1983, p. 81). From this, Coombs concludes "a reason for doing $A$ is a fact about $A$ which, if it were rationally considered by the agent, would lead her to prefer doing $\mathrm{A}$ to not doing $\mathrm{A}$, other things being equal" (1987, p. 7).

It is quite likely that Sher and Bennett could agree with Coombs' conception of a reason as it stands in the previous quotation. Coombs' account differs, however, in the explication of how reasons have motivating force. Recall that within Darwall's scheme, reasons have both a normative aspect and a motivational one. Reasons motivate, Coombs claims, because we have various motivational states that are stimulated when confronted with various facts about the world. These motivational states include things like wants, "desires, interests, appreciations, preferences, values, appetites, ideals and principles" $(1987$, p. 7$)$. Coombs goes on, "facts about an action motivate when considered by the agent because they pick out some feature of the action that is wanted by the agent" (1987, p. 7). ${ }^{4}$

Of course, neither Coombs nor Darwall are the first to argue for the central place of wants and desires. David Hume (see, for example, Hume 1965 edn.), writing two hundred years ago, argued strongly for the limited motivating power of pure reason. And I suspect this insight would be obvious to most of us were we to take off our philosopher's hat. The simple fact that I am in a grocery store does not provide me with reason to buy groceries. This fact only gives me reason to act if there is some motivational energy that comes with it (I am hungry, I am short on groceries at home, I've been sent to the store by someone else to pick something up, etc.). 
I do not wish to delve into Coombs' theory any more deeply than I have. I have raised it only to show how values (including wants, appetites, desires, etc.) play a crucial role in how we respond to reasons. In responding to Coombs' talk, Barbara Houston (1997) asks the important question that I am asking of Sher and Bennett: for whom are the reasons good ones? In exploring this question, Houston borrows a distinction from Derek Parfit (1984, p. 143) and Thomas Nagel (1986, p. 152-53) between agent-neutral reasons and agent-relative ones.

Houston claims that there are some reasons that all (or most all) humans will find good because there are basic needs we all share (nourishment, shelter, etc.). In this sense the reasons are agent-neutral because they apply to all, equally. However, there are also classes of reasons that some will respond to and some will not. These ones, thus, are agent-relative. What is important about these agentrelative reasons is that someone can recognize there to be good reasons for an action and yet be unmoved by those reasons. I can, for example, appreciate that there are good reasons why someone would want to become a doctor (one gets to serve one's community, one gets to earn lots of money thus allowing for a choice of life-style, there are rewards in helping and serving people, etc.). And while I recognize all of these as good reasons, none of them would be sufficient to lead me into becoming a doctor. The reasons are good ones, but I do not respond to them as others might.

To conclude this section, I want to summarize the two different positions taken by Sher and myself. Sher is arguing that autonomy involves responding to good reasons. I agree. Sher would also claim that to qualify as a good reason, a reason must meet some standard of good thinking. I would agree to this as well. Where Sher's account falters is in his lack of explanation of how one is moved to act based upon these reasons. He seems to think that mere perception of a good reason is sufficient (as though all good reasons were of the agent-neutral kind). In a sense I agree, but only if we understand 'reason' to include some kind of motivational aspect. This, in turn, must take into account the particular wants, desires and values that the individual agent holds. Sometimes a reason will be a good one for nearly all human beings (there are some motivational states that nearly all human beings share). But more frequently, a reason will only be judged good if it picks out some state of affairs that is desired by a particular individual.

Sher's lack of clarity on this last point leads him to an impoverished notion of autonomy. Because he does not see the importance of one's values in responding to reasons, he (and Bennett) see no problem in instilling particular values in students. He claims that autonomy is not being violated on condition that the student retains the capacity to see good reasons for holding the values later in life. 
But their position is in danger of being circular because there can be cases in which it is the holding of those values to begin with that will make the reasons good ones ("good" here meaning that the agent's perception of the reason will move her to respond to it).

\section{Autonomy with Authenticity}

To see a conception of autonomy that includes authenticity, we can look to Stanley Benn's book, $A$ Theory of Freedom. In this work, Benn claims that a pre-requisite for autonomy is what he terms autarchy. The autarchic person is one who is able to rationally critique choices and to weigh their relative merits (Benn, 1988, p. 170-75). He then goes on to distinguish between three types of autarchic persons.

Benn first makes the distinction between those with a nomos and those without. By nomos, he means some kind of law or ordering principle that gives coherence and consistency to a system of beliefs and values. The autarchic person who lacks this nomos is labelled anomic. While having the capacity to reflect upon beliefs and so to order one's belief system, the anomic person does not so reflect or act. An example might be an extreme hedonist whose only concern is pleasure in the moment. This individual has the rational capacity to see how his actions relate to other people and other future states for himself. However, since nothing else but immediate pleasures matter, there is nothing that living by a nomos could offer this person. Most, I think, would agree with Benn that without some nomos, there is no autonomy.

Where Benn and Sher would disagree, I think, is whether the combination of autarchy and a nomos are sufficient for autonomy. Benn definitely thinks not. For Sher, the answer would depend on whether the nomos was a reasonable one; that is, whether there are good reasons to accept such an ordering principle. The distinction that Benn proceeds to make here is very instructive in highlighting what Sher's conception of autonomy is lacking.

Given both autarchy and a nomos, Benn then distinguishes between the autonomous and the heteronomous person. The latter is one who unthinkingly and uncritically adopts the nomos of her society. Benn's example is the well-trained, well-drilled soldier whose values and "beliefs are introjected uncritically and unexamined from his social milieu" (1988, p. 179). According to Sher, the heteronomous agent is one who acts from good reasons (assuming that the nomos is a reasonable one). Thus, for Sher, this is an instance of autonomy. But, as Benn acknowledges, the source of that goodness is not one's own, it is borrowed. For 
Benn, the autonomous person is one who reflects upon the interplay of different beliefs within her belief system and so critically constructs the nomos (what I think might more accurately be described as critically re-constructing the nomos). Instead of just accepting the values that society offers her, the autonomous agent will look at the implications of holding a given value, how it relates to other values she holds dear and to consider this new value in light of all other relevant considerations. A good reason for $\mathrm{x}$ is one that links $\mathrm{x}$ to some other consideration that $I$ value and $I$ judge to be worthwhile. We might want to think of Benn's position in light of Quine's metaphor of a web of belief. All of our values and beliefs hang together as though connected by a web. None of the values or beliefs is foundational, beyond critique. Rather, everything is open to critique by reference to the other values and beliefs that comprise the web (Quine 1962). Thus there are good reasons for $\mathrm{x}$ when, within the web of my belief/value system, there are enough connections between $\mathrm{x}$ and other things that $I$ judge to have value, to warrant a choice of $\mathbf{x}$.

Here, finally, we seem to have found something personal, authentic, in autonomy. Throughout the paper, I have been following the common conception that autonomy involves responding to reasons. However, I questioned what exactly this entails. I have argued that we respond to reasons by recognizing some feature of the world that overlaps with some desire/value that we have. Thus, if autonomy is going to be at all personal, the desires/values we hold must be authentic ones. Within Benn's framework we have seen that by critically re-constructing our own nomos, we can be said to be holding authentic values. While this does not guarantee that we will be autonomous (let alone that we will act in a morally appropriate fashion), it is a necessary condition for that autonomy. It is important to note here that one can still hold the same values as one's parents or society. To critically re-construct the nomos does not necessarily mean changing one's values. Rather, what changes are the reasons why one holds the values one does.

In order to be autonomous, we must hold authentic values. For values to be authentic, we must be able to rationally critique them in some way. There is nothing in Sher and Bennett's scheme that makes such a critique impossible. Rather, DME makes it more unlikely. Consider how, by smoking or drinking, parents can set an example that their children are likely to follow. The same can be seen in terms of values as well. Children growing up in racist, sexist or homophobic environments are far more likely to adopt these values themselves than children raised in environments free of these attitudes. And while it is a logical possibility that children raised with these attitudes can later call them into question, 
it is difficult, for at least two reasons. The first is that such values can become foundational to our entire worldview. Thus, not only will a particular value need to be questioned, but also whole structures of belief and value that are built upon it. This is much more difficult. The second reason is that if a belief or value is engrained from when we are young, we often do not 'see' it as merely an option and one that can be questioned. Rather it is simply reality, hidden from our critical reflection. Pre-rationally conditioning beliefs does not necessarily mean that they cannot later be questioned. But such conditioning does make this questioning far more difficult and less likely to be attempted. In pre-rationally conditioning students to favour particular values or beliefs, we need to be aware of these potential dangers. These dangers are ones that Sher and Bennett do not seem to fully appreciate.

\section{Conclusion}

Recall that Sher and Bennett's central question was whether directive moral education is indoctrinative. I want to point us back to why we think indoctrination is such a bad thing and, conversely, why autonomy is so important. Both our moral and political systems are predicated on the individual being allowed to choose for herself what goals she will pursue in her life. This will involve choosing for oneself what are the goods in life and how best to pursue those goods. To the extent that we condition students to favour one path over another, we are reducing their opportunity for deciding themselves how best to live life.

A DME, like the one outlined by Sher and Bennett is, I have argued, questionable. It rests upon an impoverished notion of autonomy and consequently, a weak conception of moral maturity. To conclude, I want to explore two criteria by which DME can be judged. The first is to explore Sher and Bennett's central concern, whether such an educational project is morally appropriate. I have given reasons to at least doubt this. If the values we are conditioned to hold when we are young are not reasonably accessible to our critical scrutiny, then, as adults, our autonomy is lessened. It is not sufficient to point to the fact that the adult will be able to respond to reasons because, as I have argued, the reasons we respond to are dictated, in large part, by the values we hold.

In exploring Sher and Bernett's work, I have tried to point out that there is a danger in DME that they do not appear to be fully aware of. By not being clear about what responding to reasons entails, and the possibility of conditioned values becoming foundational, Sher and Bennett do not see the potential for DME to be indoctrinative. By recognizing authenticity as being a key component of autonomy, 
we are more alert to these dangers and so, we are in a morally preferable situation with regard to our students.

The second criterion by which I want to measure DME is on its pedagogical usefulness. I began the paper by talking about moral maturity, questioning what it is to be a morally mature person. The distinction Benn makes between the autonomous and the heteronomous person is informative here. Recall that the former critically (re-)constructs his nomos, while the latter merely accepts the nomos that is offered by his society. All other things being equal, the first is obviously the preferable state to be in (assuming that we value autonomy). As such, it is the one we should be striving to bring our students to through moral education. DME does not necessarily lead to heteronomy (as I have argued throughout the paper, some DME is necessary). But unless we realize the crucial role that values play in responding to reasons, DME runs a very real risk of it. As educators, we want our students to be autonomous in Benn's sense. This is far more likely to be achieved if we understand autonomy as necessarily incorporating authenticity.

\section{References}

Ayim, Maryann (1991). Dominance and affiliation: Paradigms in conflict. Informal Logic, 13 (2), 79-88.

Benn, Stanley (1988). A Theory of Freedom. Cambridge: Cambridge University Press.

Boyd, Dwight (1992). The moral part of pluralism as the plural part of moral education. In F. Power and D. Lapsley (Eds.) The Challenge of Pluralism.

Carr, David (1991). Educating the Virtues: An Essay on the Philosophical Psychology of Moral Development and Education. London: Routledge.

Coombs, Jerrold (1987). Education and practical rationality. In Nicholas C. Burbules (Ed.) Philosophy of Education, 1986. Normal, Ill.: Philosophy of Education Society, p. 3-20.

Darwall, Stephen (1983). Impartial Reason. Ithaca, N.Y.: Cornell University Press.

Hare, R.M. (1964). Adolescents into adults. In T.H.B. Hollins (Ed.), Aims in Education. Manchester: Manchester University Press), p. 47-70.

Herman, Barbara (1993). The Practice of Moral Judgment. Cambridge, Mass.: Harvard University Press.

Houston, Barbara (1987). Practical Rationality and Morality. In Nicholas C. Burbules (Ed.) Philosophy of Education, 1986. Normal, Ill.: Philosophy of Education Society, p. 2128.

Hume, David (1965). Hume's Ethical Writings. A. MacIntryre (Ed.). London: Collier Books.

McClellan, James E. (1987). Coombs and Columbus. In Nicholas C. Burbules (Ed.) Philosophy of Education, 1986. Normal Ill.: Philosophy of Education Society, p. 2936.

Metcalf, Lawrence (Ed.) (1971). Values Education. Washington, D.C.: National Council for 
Social Studies.

Nagel, Thomas (1986). The View From Nowhere. Oxford: Oxford University Press.

Noddings, Nel (1984). Caring: A Feminine Approach to Ethics and Moral Education.

Berkeley: University of California Press.

Parfit, Derek (1984). Reasons and Persons. Oxford: Oxford University Press.

Quine, W.V. (1962). From A Logical Point of View, $2^{\text {nd }}$ edn. Cambridge: Harvard University Press.

Sher, George and Bennett, William J. (1982). Moral Education and Indoctrination. Journal of Philosophy, 79, p. 665-677.

Sher, George (1997). Beyond Neutrality: Perfectionism and Politics. Cambridge: Cambridge University Press.

Siegel, Harvey (1991). Indoctrination and education. In B. Spiecker \& R Straughan (Eds.)

Freedom and Indoctrination in Education: International Perspectives, p. 30-41.

Strike, Kenneth (1982). Liberty and Learning. Oxford: Martin Robertson.

Wilson, John (1990). New Introduction to Moral Education. London: Cassell.

\section{Notes}

1. I would like to thank Jerrold Coombs, Francis Schrag and the anonymous reviewers at Paideusis, all of whom offered insightful comments on various drafts of this paper.

2. I take these terms from Kenneth Strike. He sees autonomy "as the capacity to make and act on independent reasoned judgements. Authenticity, by contrast, is a matter of choosing or acting consistently with one's nature, of being one's self, not being phony" (1982, p. 156). While Strike (and most other commentators) sees both as worthwhile, he claims autonomy is a fundamental value, authenticity is not. I disagree with Strike that the two concepts are wholly distinct. As I will show, autonomy without authenticity is a hollow one. The heart of my objection to Sher and Bennett's position is that their directive moral education, while perhaps developing certain desirable virtues, does so at the expense of authenticity (and so, at the expense of autonomy).

3. I want to be careful here not to be seen as implying that simply because one is responding to values that are somehow authentic that this guarantees the moral quality of an act. People can hold morally problematic values. Further, even those with reasonable values can misread situations and so act in morally questionable ways. I am, instead, claiming that this authenticity is a necessary condition of an act being autonomous.

4. It is by no means uncontroversial that reasons can and should be divided into these normative and motivational aspects. James McClellan, for example, writes the following in response to Darwall and Coombs' position: "The moral is this: The distinction between motivating and justifying reasons rests on an idealist metaphysics. Get rid of it!" (1987, p. 33). McClellan backs up this claim by arguing that the first thing one learns in studying counselling is to never ask someone to justify their actions. But his arguments rest on the usefulness of the distinction. In counselling, he claims, asking for justification is counterproductive. Whether or not this is true can be left aside for the moment. What can be seen 
from his claim is that one must look to the specific context to see if the distinction is usefully drawn. To accept that this question needs to be asked is to accept that such a distinction can be made. Thus he is defeating his own argument that the distinction rests on an idealist metaphysics. The question is not whether such a distinction exists but whether it is useful. As Coombs' analysis has shown, there is some use in making it. Thus, the motivating aspect of reasons must be accounted for. Coombs' position provides such an account. Sher and Bennett's does not.

\section{Author}

Scott Priestman is a doctoral candidate in the Department of Educational Studies, UBC, finishing a dissertation on the role impartiality plays in moral reasoning. His Master's thesis, also at $\mathrm{UBC}$, concerns teaching for wisdom.

priestma@interchange.ubc.ca 